\title{
A Cost-Utility Analysis of Secondary Prophylaxis for Variceal Hemorrhage
}

Joel H. Rubenstein, M.D., Glenn M. Eisen, M.D., M.P.H., and John M. Inadomi, M.D.

Division of Gastroenterology, University of Michigan Health System, Ann Arbor, Michigan; and Division of Gastroenterology, Oregon Health Sciences University, Portland, Oregon

BACKGROUND: Secondary prophylaxis for esophageal variceal hemorrhage $(\mathrm{VH})$ is recommended, but there has never been a cost-utility analysis of its implementation.

OBJECTIVE: The objective was to compare the cost utility of various strategies for the secondary prophylaxis of VH including (a) observation alone, (b) medical therapy (MED), (c) endoscopic band ligation (EBL), (d) endoscopic band ligation plus medical therapy ( $E B L+M)$, and (e) transjugular intrahepatic portosystemic shunt (TIPS), and to examine the effect of adherence on these strategies.

METHODS: $\quad$ A Markov model was developed for all five strategies, and included surveillance, risk of hepatic encephalopathy, complications, and nonadherence. Data sources: Published literature and the Health Care Financing Administration. Target population: People with cirrhosis and a history of controlled VH. Time horizon: Three years. Perspective: Third-party payer. Outcome measures: Incremental cost-effectiveness ratios for quality-adjusted life-years (QALYs) gained.

RESULTS OF Combination EBL $+M$ was the optimal strategy, dominating all other strategies including BASE-CASE ANALYSIS: observation, meaning that it was more effective and less expensive than the others. In addition, EBL alone dominated observation and TIPS in terms of QALYs, and MED alone dominated the strategy of observation in terms of QALYs.

RESULTS OF SENSITIVITY Important variables affecting the optimal strategy were the odds ratio (OR) of VH with EBL ANALYSIS: compared to MED, the OR of VH with EBL + M compared to EBL, and patients' preferences regarding taking the medication as reflected in the associated toll exacted on the health state utility. Variations in these parameters within the range of clinical plausibility allowed EBL or MED to become the optimal strategy. TIPS was the optimal strategy only if adherence rates for all strategies were less than $12 \%$.

RESULTS OF Neither observation nor TIPS was ever the optimal strategy, and EBL + M was optimal in $62 \%$ of MONTE CARLO ANALYSIS: cases. If the variables identified in the sensitivity analysis were controlled, then $E B L+M$ was optimal in $95 \%$ of cases.

CONCLUSIONS: TIPS should be reserved only for patients with very poor adherence. Otherwise, patients are best served by medications, EBL, or a combination of both, depending on the comparative rates of rebleeding with each and patients' preferences regarding medical therapy. The redundancy of combination band ligation plus medical therapy can improve outcomes, particularly in the setting of poor patient adherence.

\section{INTRODUCTION}

Variceal hemorrhage (VH) is a major cause of death among patients with cirrhosis. Among those who have survived a previous $\mathrm{VH}$, the rate of rebleeding is up to $60 \%$ per year $(1,2)$. Historically, VH has carried with it a mortality rate as high as $50 \%(3,4)$. Even with the advent of intensive care, vasoactive medications, and endoscopic therapies, the risk of death with VH is still about $20 \%$ per episode $(5,6)$.

The American College of Gastroenterology recommends secondary prophylaxis of $\mathrm{VH}$ (i.e., prophylaxis after survival from a first $\mathrm{VH}$ ) with medical or endoscopic therapy (7).
Medical therapy with nonselective beta-adrenergic antagonists with or without long-acting nitrates has been shown to be an efficacious secondary prophylaxis in terms of preventing recurrent $\mathrm{VH}$ (1). A meta-analysis found that endoscopic sclerotherapy is more efficacious than medical prophylaxis, and another found that endoscopic band ligation (EBL) is more efficacious than sclerotherapy $(8,9)$. However, the only three randomized controlled trials comparing EBL to medical therapy have conflicting results (10-12). Transjugular intrahepatic portosystemic shunts (TIPSs) have been shown to be more efficacious than endoscopic therapy in preventing 
variceal rebleeding, but have a considerably higher rate of hepatic encephalopathy (HE) (13). Finally, only one study has examined a combination medical therapy and band ligation, and found that the risk of rebleeding with that strategy was less than with band ligation alone (14).

The ideal strategy of secondary prophylaxis of $\mathrm{VH}$ depends not only on the efficacy found in trials, but also patient adherence, complication rates, costs, and patient preference for different health states (i.e., utilities) (15). Evaluating all of these outcomes in a trial with arms for each of the prophylactic strategies would require a prohibitively large number of subjects. Furthermore, measuring patient adherence in trials is fraught with methodological quandaries. In such cases, decision analysis based on mathematical modeling of a hypothetical cohort of patients is an ideal tool. The only previously published decision analysis of secondary prophylaxis of VH compared combination endoscopic and medical therapy to TIPS, but did not evaluate the strategies of no prophylaxis, medical therapy alone, or endoscopic therapy alone, and did not account for adherence rates (16). Furthermore, that study was limited to a cost-effectiveness analysis (examining the cost per VH prevented), rather than a cost-utility analysis (the cost per quality-adjusted life-years saved).

We developed a Markov model and performed a cost-utility analysis comparing strategies of observation, medical therapy, EBL, EBL + medical therapy, and TIPS, and evaluated the effect of nonadherence on the preferred strategy.

\section{METHODS}

\section{Patients}

The hypothetical cohort consisted of patients with a history of controlled, bleeding esophageal varices at the time of enrollment. Because the model was based on the published empiric evidence of the various secondary prophylactic strategies, the hypothetical cohort consisted of men with Child's Class B cirrhosis and an average age of $50 \mathrm{yr}(2,10-12,14,15,17-26)$. Patients were excluded if they were intolerant of medications, or if they had persistent HE at the time of enrollment. The analysis followed the cohort for $3 \mathrm{yr}$, as there are no data on longer-term outcomes for the various prophylactic strategies.

\section{Model}

Decision analysis was modeled by creating a Markov chain with DATA 4.0 software (TreeAge, Williamstown, MA). A Markov model is a mathematical simulation of hypothetical patients with a disease process over time. Unlike decision trees, Markov models are recursive in that they allow movement back and forth between health states. A simplified schematic of the model is shown in Figure 1. The actual model contains 1,383 branches, accounting for the natural history of patients with controlled $\mathrm{VH}$, the various strategies for secondary prophylaxis, nonadherence, iatrogenic complications, surveillance in the EBL and TIPS arms, and undetected TIPS dysfunction. The appendices contain more

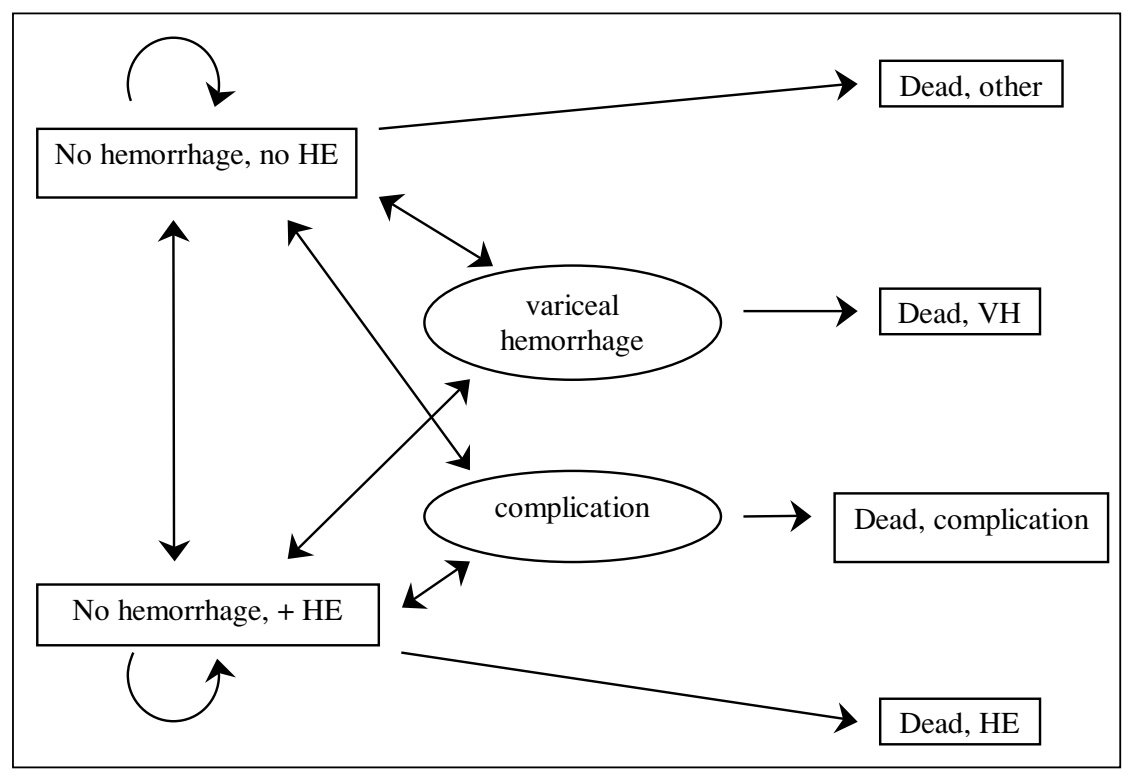

$\mathrm{HE}=$ hepatic encephalopathy, $\mathrm{VH}=$ variceal hemorrhage

Figure 1. Simplified schematic of Markov model. At any given cycle, hypothetical patients start in one of the Markov health states (rectangles), and have a specified rate of transition (arrows) to other Markov states, either directly, or via transition states (ovals). All patients are assumed to begin in the Markov state of "no hemorrhage, no HE." Each state has an associated cost and utility, and many transitions carry costs and tolls on utility as well. The simplified schematic does not show the additional states representing the EBL series, endoscopic surveillance for EBL, ultrasound surveillance for TIPS, undetected TIPS dysfunction, nor nonadherence. 
detailed information on the model, including structure, transition probabilities, costs, and Monte Carlo analysis. The length of each model cycle was $2 \mathrm{wk}$.

\section{Natural History}

Outcomes without any secondary prophylaxis, but with observation alone (OBS) were examined. Patients could rebleed from esophageal varices, requiring admission to the hospital, octreotide infusion, and endoscopic treatment to control the hemorrhage. Although in the real world, combinations of strategies may be practical, our aim was to compare the individual strategies in order to detect the advantages and weaknesses of each. Therefore, in each of the strategies, if patients survived a $\mathrm{VH}$, they still continued with the same strategy, i.e., there was no cross over for failed strategies. It was assumed that the risk of $\mathrm{VH}$ stayed constant with time.

Patients could also develop persistent HE. They could die as a result of $\mathrm{VH}$, as a result of a complication of a procedure, with cirrhosis but without HE, or with cirrhosis and HE. Liver transplantation was not considered an option in any arm.

\section{Prophylactic Strategies}

MEDICATIONS (MED). A strategy of medical prophylaxis was defined as treatment with nonselective beta-adrenergic receptor antagonists, titrated to resting heart rate and blood pressure in the outpatient setting, without the use of invasive hemodynamic measurements. The additional benefit of using combination beta-blockers and nitrates was examined in a sensitivity analysis. In each cycle, the patients had a chance of being adherent to the degree necessary to achieve similar results as in randomized controlled trials. Otherwise, they were considered nonadherent, and reverted to the same risks and costs as the observation arm, but were not given the opportunity to cross over to any other strategy. Also, in each cycle, the patients had a chance to adhere to the medical regimen or not, independent of adherence in the previous cycle. The analysis assumed perfect knowledge regarding a patient's adherence. No distinction was made between patient adherence with physician advice, and physician adherence with administering standard care within each strategy.

ENDOSCOPIC BAND LIGATION (EBL). Patients in the EBL arm underwent the outpatient procedure every $2 \mathrm{wk}$ until eradication of the varices, or until they were too small to be ligated. If patients became nonadherent prior to completion of the series, they reverted to the same risks and costs as the observation arm. Endoscopic surveillance was scheduled every 6 months after the completion of the EBL series. If varices were discovered, patients underwent a shorter series of EBL. If patients were nonadherent with surveillance, and had undetected recurrence of varices, they reverted to the observation arm. However, at the next surveillance interval of 6 months, patients with undetected recurrence were given the chance to undergo EBL again if they adhered at that time. If patients survived a rebleed, they received the opportunity to undergo a similar number of EBL sessions as with their initial VH.

ENDOSCOPIC BAND LIGATION PLUS MEDICATIONS $(\mathrm{EBL}+\mathrm{M})$. Patients could receive both EBL and medications. For simplicity of the model, during the few weeks of the EBL series, patients were assumed to be adherent with medications if they were adherent with EBL. Otherwise, adherence with EBL and medications were modeled independently of each other, so that patients could adhere to either, both, or neither therapy. In the sensitivity analyses, EBL + $\mathrm{M}$ was not allowed be less efficacious than MED alone.

TRANSJUGULAR INTRAHEPATIC PORTOSYSTEMIC SHUNT (TIPS). Patients in the TIPS arm underwent placement of the TIPS immediately upon enrollment (after control of the index $\mathrm{VH}$ ), received a postprocedural Doppler ultrasound the next day, and if acute occlusion was found, underwent revision of the TIPS; all patients were assumed to be adherent with initial TIPS placement. Subsequently, Doppler ultrasound was performed every 3 months to survey for TIPS dysfunction, but there was a chance that patients could be nonadherent with any given survey. The sensitivity and specificity of Doppler ultrasound was assumed to be imperfect; patients could have undetected TIPS dysfunction. In addition, if TIPS dysfunction was identified by the ultrasound, patients underwent hepatic venography to confirm the diagnosis prior to TIPS revision. If TIPS dysfunction presented with a recurrent VH, patients underwent TIPS revision. Patients with a functional TIPS had a higher rate of developing persistent HE than the patients in other arms.

\section{Transitions}

Transition rates between the Markov health states were derived from the published literature. The MEDLINE and EMBASE databases were searched from 1966, and from 1988, respectively, to 2002 using the terms esophageal varices, ligation, transjugular intrahepatic portosystemic shunt, complication, hepatic encephalopathy, liver cirrhosis, mortality, prognosis, natural history, clinical trials, follow-up studies, and meta-analysis. Additional articles were identified by cross-referencing those identified by the database search. Base-case values were chosen from medians of the published literature. Transition rates for the natural history were modeled as simple rates. The model derived transition rates for the prophylactic strategies based on the transition rates in the natural history, and corresponding odds ratios (ORs) for the specific strategy. In addition to the base-case scenario, sensitivity analyses were performed over the entire range found in the published literature (Table 1). Published meta-analyses were used to derive the ORs of VH with medications and with TIPS, and the OR of encephalopathy with TIPS. The three clinical trials comparing medication with band ligation have discrepant results. In the base-case scenario, we assumed the $\mathrm{OR}$ of $\mathrm{VH}$ matched that in the trial by Lo et al. because that 
Table 1. Model Assumptions

\begin{tabular}{|c|c|c|c|c|}
\hline Variables & Base Case & Low Value & High Value & References \\
\hline $\begin{array}{l}\text { Variceal hemorrhage }(\mathrm{VH}) \\
\text { OBS annual rate } \\
\text { OR MED: OBS } \\
\text { OR EBL: MED } \\
\text { OR EBL + M: EBL } \\
\text { OR TIPS: EBL } \\
\text { Mortality rate per VH }\end{array}$ & $\begin{array}{l}0.500 \\
0.435 \\
0.450 \\
0.352 \\
0.263 \\
0.208\end{array}$ & $\begin{array}{l}0.335 \\
0.290 \\
0.240 \\
0.290^{*} \\
0.192 \\
0.050\end{array}$ & $\begin{array}{l}0.600 \\
0.590 \\
2.610 \\
1^{*} \\
0.357 \\
0.500\end{array}$ & $\begin{array}{l}(2,17-22) \\
(1,23,42,50) \\
(8-12) \\
(14) \\
(13,38,39,44) \\
(3-6,41,43,48,51-53)\end{array}$ \\
\hline $\begin{array}{l}\text { Hepatic encephalopathy (HE) } \\
\text { OBS annual rate } \\
\text { OR TIPS: OBS }\end{array}$ & $\begin{array}{l}0.127 \\
2.080\end{array}$ & $\begin{array}{l}0.049 \\
1.490\end{array}$ & $\begin{array}{l}0.307 \\
3.330\end{array}$ & $\begin{array}{l}(15,24,25,38,54-60) \\
(13,39)\end{array}$ \\
\hline $\begin{array}{l}\text { Mortality in absence of VH } \\
\text { Annual rate without HE } \\
\text { OR with HE: no HE }\end{array}$ & $\begin{array}{l}0.061 \\
1^{*}\end{array}$ & $\begin{array}{l}0.007 \\
1^{*}\end{array}$ & $\begin{array}{l}0.618 \\
2.550\end{array}$ & $\begin{array}{l}(1,3,5,45,46,51,61-64) \\
(5,63,65)\end{array}$ \\
\hline $\begin{array}{l}\text { Endoscopic band ligation } \\
\text { No. of sessions in initial series (mean, SD) } \\
\text { No. of sessions if recurrence (mean, SD) } \\
\text { Annual rate of variceal recurrence } \\
\text { EBL morbid complication rate } \\
\text { EBL mortal complication rate } \\
\text { EGD morbid complication rate } \\
\text { EGD mortal complication rate }\end{array}$ & $\begin{array}{l}3.6 \pm 1.1 \\
2.3 \pm 0.6 \\
0.417 \\
0.008 \\
0.00238 \\
0.0040 \\
0.0003\end{array}$ & $\begin{array}{l}0.342 \\
0.00143 \\
0.0003^{*} \\
0.0013 \\
0.000071\end{array}$ & $\begin{array}{l}0.504 \\
0.0572 \\
0.00476^{\ddagger} \\
0.0135 \\
0.0005\end{array}$ & $\begin{array}{l}(9,11,14,24,66,67) \\
(14) \\
(14,68-70) \\
(9,11,12,47,71-74) \\
(9) \\
(75-77) \\
(75-77)\end{array}$ \\
\hline $\begin{array}{l}\text { TIPS } \\
\text { Technical failure rate, initial TIPS } \\
\text { Technical failure rate, TIPS revision } \\
\text { Annual rate of dysfunction (dysfxn) } \\
\text { Probability of dysfxn if rebleeding } \\
\text { Sensitivity, ultrasound for dysfxn } \\
\text { Specificity, ultrasound for dysfxn } \\
\text { TIPS morbid complication rate } \\
\text { TIPS mortal complication rate } \\
\text { Venography morbid complication rate } \\
\text { Venography mortal complication rate }\end{array}$ & $\begin{array}{l}0.034 \\
0.026 \\
0.593 \\
1 \\
83.5 \% \\
88.5 \% \\
0.22 \\
0.015 \\
0.075 \\
0\end{array}$ & $\begin{array}{l}0 \\
0 \\
0.248 \\
0.987 \\
53.2 \% \\
61.6 \% \\
0.10 \\
0 \\
0.008 \\
0\end{array}$ & $\begin{array}{l}0.090 \\
0.075 \\
0.830 \\
1 \\
100 \% \\
100 \% \\
0.53 \\
0.028 \\
0.09 \\
0.015^{*}\end{array}$ & $\begin{array}{l}(13,38,78-80) \\
(58,79,81-83) \\
(24,25,44,54,55,58,79,81-85) \\
(44,79,81,83,84,86) \\
(25,82,85,87-89) \\
(25,82,85,87-89) \\
(38,49,78,80,81) \\
(13,49,78-80) \\
(49,78,90) \\
(49,90)\end{array}$ \\
\hline $\begin{array}{l}\text { Adherence rates } \\
\text { Medications for } 2 \text { wk } \\
\text { EBL or EGD (each session) } \\
\text { Survey ultrasound } \\
\text { OR of adherence if HE: no HE }\end{array}$ & $\begin{array}{l}100 \% \\
100 \% \\
100 \% \\
100 \%\end{array}$ & $\begin{array}{l}0 \% \\
0 \% \\
0 \% \\
0 \%\end{array}$ & $\begin{array}{l}100 \% \\
100 \% \\
100 \% \\
100 \%\end{array}$ & $\begin{array}{l}* \\
* \\
* \\
*\end{array}$ \\
\hline $\begin{array}{l}\text { Costs } \\
\text { Cirrhosis without VH or HE (annual) } \\
\text { Additional cost for HE (annual) } \\
\text { Variceal hemorrhage } \\
\text { Medications (annual) } \\
\text { EBL (per session) } \\
\text { EBL complication } \\
\text { Survey EGD } \\
\text { EGD complication } \\
\text { TIPS placement } \\
\text { TIPS complication } \\
\text { Survey Doppler ultrasound } \\
\text { Venography without TIPS } \\
\text { Venography complication }\end{array}$ & $\begin{array}{r}\$ 471^{\dagger} \\
\$ 19,280^{\dagger} \\
\$ 8,832^{\dagger} \\
\$ 86^{\dagger} \\
\$ 407^{\S} \\
\$ 6,714^{\dagger} \\
\$ 407^{\S} \\
\$ 6,347^{\dagger} \\
\$ 2,606^{\dagger} \\
\$ 6,104^{\dagger} \\
\$ 134^{\S} \\
\$ 1,109^{\S} \\
\$ 6,184^{\dagger}\end{array}$ & $\begin{array}{r}\$ 235 \\
\$ 9,640 \\
\$ 4,416 \\
\$ 43 \\
\$ 203 \\
\$ 3,357 \\
\$ 203 \\
\$ 3,173 \\
\$ 1,303 \\
\$ 3,052 \\
\$ 67 \\
\$ 555 \\
\$ 3,092\end{array}$ & $\begin{array}{r}\$ 942 \\
\$ 38,561 \\
\$ 17,664 \\
\$ 172 \\
\$ 814 \\
\$ 13,428 \\
\$ 814 \\
\$ 12,694 \\
\$ 5,212 \\
\$ 12,207 \\
\$ 268 \\
\$ 2,218 \\
\$ 12,369\end{array}$ & $\begin{array}{l}\ddagger \\
\vdots \\
\vdots \\
\vdots \\
\vdots \\
\ddagger \\
\ddagger \\
\vdots \\
\vdots \\
\vdots \\
\ddagger \\
\ddagger \\
\vdots \\
\vdots \\
\vdots \\
\vdots\end{array}$ \\
\hline $\begin{array}{l}\text { Utilities } \\
\text { Cirrhosis with history of VH } \\
\text { Cirrhosis with HE and history of } \mathrm{VH}\end{array}$ & $\begin{array}{l}0.67 \\
0.56\end{array}$ & $\begin{array}{l}0.56 \\
0.30\end{array}$ & $\begin{array}{l}0.83 \\
0.67\end{array}$ & $\begin{array}{l}(29,30) \\
(29-32)\end{array}$ \\
\hline $\begin{array}{l}\text { Utility tolls (for } 2 \text { weeks) } \\
\text { Variceal hemorrhage } \\
\text { Medications } \\
\text { EBL complication } \\
\text { EGD complication } \\
\text { TIPS complication } \\
\text { Venography complication }\end{array}$ & $\begin{array}{r}25 \% \\
2 \% \\
25 \% \\
25 \% \\
25 \% \\
25 \%\end{array}$ & $\begin{array}{l}0 \% \\
0 \% \\
0 \% \\
0 \% \\
0 \% \\
0 \%\end{array}$ & $\begin{array}{l}80 \% \\
50 \% \\
80 \% \\
80 \% \\
80 \% \\
80 \%\end{array}$ & $\begin{array}{l}* \\
* \\
* \\
* \\
* \\
* \\
*\end{array}$ \\
\hline
\end{tabular}

OBS $=$ observation alone, $\mathrm{MED}=$ medical therapy, $\mathrm{EBL}=$ endoscopic band ligation, $\mathrm{EBL}+\mathrm{M}=$ combination EBL plus medical therapy, TIPS $=$ transjugular intrahepatic portosystemic shunt, EGD = diagnostic esophagogastroduodenoscopy.

${ }^{*}$ Author consensus, see Appendices for details.

$\S 2001$ median national Medicare reimbursement.

${ }^{\dagger}$ Microcosting of pseudo-bills; see Appendix C for details

‡Low value derived by halving, and high value derived by doubling base case. 
was the only protocol that did not use invasive hemodynamic measurements to titrate medications $(10-12)$. The rates of adherence with all strategies were taken to be $100 \%$ in the base-case scenario, and each was examined independently of the other with sensitivity analyses ranging from $0 \%$ to $100 \%$.

\section{Costs and Utilities}

Direct health costs were estimated using the microcosting technique; specifically, hypothetical pseudo-bills were created to estimate resource utilization (27). The associated year 2001 median national reimbursement rates from the Health Care Financing Administration were used. Medication costs were estimated using average wholesale prices from 2002, adjusted to year 2001 dollars using the consumer price index (28). Direct non-health-care costs (such as patient transportation costs to and from clinic visits) and indirect costs (such as lost wages) were not included in the analysis. Sensitivity analyses used low values derived by halving and high values derived by doubling the base case (Table 1). The outcomes were analyzed from the perspective of a third-party payer.

Utilities are ratios that reflect patient preference for particular health states; they can be thought of as one-dimensional values reflecting quality of life ranging from 0 (death) to 1 (perfect health). Utilities were estimated by using the published empiric data for cirrhosis $(29,30)$. The utility of Child's Class B cirrhosis was used to estimate the utility of having a history of controlled VH but no HE; the utility of Child's Class $\mathrm{C}$ cirrhosis was used to estimate that of a history of controlled VH with HE. Previously published utilities for encephalopathy based on expert opinion were incorporated into the sensitivity analyses $(31,32)$. VH and complications likely cause short-term decrements in the quality of life; therefore, a toll of $25 \%$ of the patient's health state utility for that 2 -wk cycle was assessed each time the patient had such a transition. Similarly, adherence to beta-blocker medications also may cause a slight, but persistent decrement in quality of life due to tolerable adverse effects such as fatigue or sexual dysfunction. Therefore, adherence to medication was associated with a $2 \%$ toll on the health state's utility. These tolls were based on author consensus, and varied over a wide range in the sensitivity analyses.

All costs and utilities were discounted at an annual rate of $3 \%$, with a sensitivity analysis from $0 \%$ to $5 \%$ (27).

\section{Sensitivity Analysis}

All of the assumptions were varied in one-way sensitivity analyses over the range found in the published literature, or in the absence of published data, over a wide range as described above. Two-way sensitivity analyses were performed for selected variables.

In order to analyze the sensitivity to multiple assumptions simultaneously, a Monte Carlo simulation was performed. Transition rates and utilities were distributed normally except those with ranges spanning at least two orders of magnitude (these were the OR of VH with EBL compared to MED, mortality rate in absence of $\mathrm{VH}$ or $\mathrm{HE}$, and $\mathrm{EBL}$ morbid complication rate); these three transitions were distributed as log-normal functions. Because the ranges of the cost variables were skewed, they were distributed as triangle functions. Adherence rates and utility tolls were held constant at the base-case values since no empiric data exist to describe their distributions.

\section{Outcomes}

The primary outcome was the incremental cost-effectiveness ratio (ICER) based on quality-adjusted life-years (QALYs) saved between competing strategies of secondary prophylaxis. ICER is defined as the difference in cost, divided by the difference in effectiveness. We defined the optimal strategy as one that provides the most QALYs at a cost of no more than $\$ 50,000$ per each additional QALY compared with the next-best strategy. Additional outcomes determined were mean cost per patient, mean QALYs, mean number of $\mathrm{VH}$, and cost per $\mathrm{VH}$ prevented.

\section{RESULTS}

\section{Natural History}

Over a time horizon of $3 \mathrm{yr}$, the natural history of a patient with a history of $\mathrm{VH}$ (as described by the observation strategy in the base-case scenario) yielded 1.44 average QALYs, and the direct health costs to a third-party payer averaged $\$ 21,100$. The model predicted that each patient experienced on average $1.56 \mathrm{VHs}$ during this time period, and the 3-yr survival was $56 \%$.

\section{Prophylactic Strategies}

In the cost-utility analysis of the base-case scenario, the strategy of EBL + M dominated all of the other strategies, including observation, meaning that EBL + M yielded more QALYs and was less expensive than the other strategies (Fig. 2, Table 2). Observation was also dominated by either EBL or

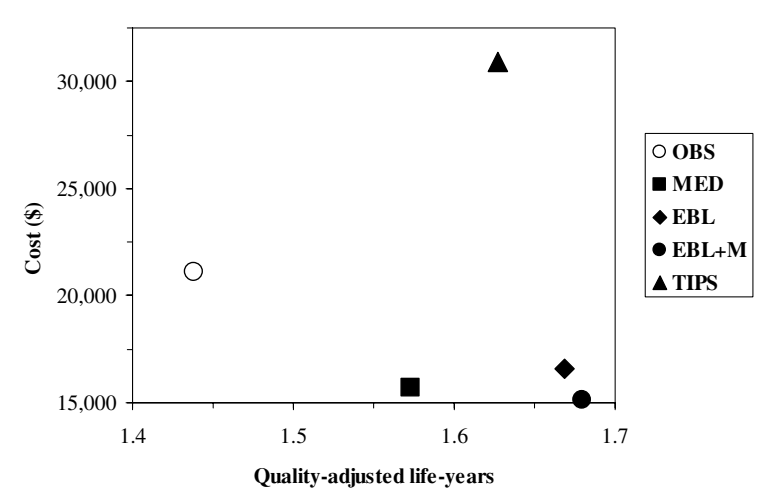

$\mathrm{OBS}=$ observation, $\mathrm{MED}=$ medical therapy, $\mathrm{EBL}=$ endoscopic band ligation, $\mathrm{EBL}+\mathrm{M}=$ combination $\mathrm{EBL}$ plus medical therapy, TIPS = transjugular intrahepatic portosystemic shunt

Figure 2. Cost utility for QALYs in base-case scenario. In this figure, more effective strategies appear toward the right, and less expensive strategies appear toward the bottom. EBL + M (filled circle) dominated all strategies, meaning it was both most effective and least expensive. 
Table 2. Results of Prophylactic Strategies

\begin{tabular}{|c|c|c|c|c|c|c|}
\hline Strategies & Cost $(\$ 1,000 \mathrm{~s})$ & QALYs & ICER QALY & VH & ICER VH & $\begin{array}{l}\text { Three-year } \\
\text { Survival (\%) }\end{array}$ \\
\hline $\mathrm{EBL}+\mathrm{M}$ & 15.1 & 1.68 & - & 0.13 & - & 82 \\
\hline MED & 15.7 & 1.57 & (Dominated) & 0.77 & (Dominated) & 71 \\
\hline EBL & 16.6 & 1.67 & (Dominated) & 0.36 & (Dominated) & 77 \\
\hline OBS & 21.1 & 1.44 & (Dominated) & 1.56 & (Dominated) & 56 \\
\hline TIPS & 30.9 & 1.63 & (Dominated) & 0.23 & (Dominated) & 77 \\
\hline
\end{tabular}

QALYs = quality-adjusted life-years, ICER = incremental cost-effectiveness ratio, $\mathrm{VH}=$ number of variceal hemorrhages experienced, EBL $+\mathrm{M}=$ combination endoscopic band ligation plus medical therapy, $\mathrm{MED}=$ medical therapy, $\mathrm{EBL}=$ endoscopic band ligation, $\mathrm{OBS}=$ observation, TIPS $=$ transjugular intrahepatic portosystemic shunt.

MED alone, and TIPS was dominated by EBL alone. TIPS yielded more QALYs than MED alone, but was relatively costly. In terms of $\mathrm{VH}$ prevention, there were diminishing gains with successively more effective strategies (Table 2). Of the $1.56 \mathrm{VHs}$ predicted in the observation arm over $3 \mathrm{yr}$, patients in the MED arm suffered 0.77, with EBL 0.36, with TIPS 0.23 , and with combination EBL $+\mathrm{M}$ only 0.13 . However, the slight advantage of TIPS over EBL in preventing VH did not translate into overall survival; EBL $+M$ was predicted to have a 3 -yr survival of $82 \%$, compared to $77 \%$ for both EBL and TIPS, $71 \%$ for MED, and $56 \%$ for observation (Table 2).

\section{Sensitivity Analyses}

ONE-WAY SENSITIVITY ANALYSES. One-way sensitivity analyses for cost utility were performed on each of the variables. Only 4 of the 52 variables demonstrated changes in the optimal strategy as defined by the strategy producing the most QALYs at no more than $\$ 50,000$ per additional QALY gained compared to the next most effective strategy (Table 3). If patients' quality of life decreased by more than $4 \%$ because of adverse effects of the medications, then EBL alone was the optimal strategy rather than $\mathrm{EBL}+\mathrm{M}$, since any benefit of medications in preventing $\mathrm{VH}$ was offset by the decrease in quality of life.

The comparative rates of VH with MED, EBL, and EBL + $\mathrm{M}$ also strongly affected the choice of optimal strategies. If the odds of experiencing a VH with EBL were greater than 1.7 times the odds with MED, then MED alone was the optimal strategy rather than EBL $+\mathrm{M}$ as in the base case. At ORs greater than 1.7, the added cost of EBL outweighed any of its added benefits.
If the odds of VH with EBL alone was less than 1.5 times the odds with $\mathrm{EBL}+\mathrm{M}$, then EBL alone was optimal. Below that OR, the decrement in quality of life caused by the medications outweighed any added benefit medications provided in preventing $\mathrm{VH}$.

$\mathrm{EBL}+\mathrm{M}$ dominated all other strategies in the base-case scenario, and adherence rates had little effect. For instance, if adherence with medications was even $1 \%, \mathrm{EBL}+\mathrm{M}$ dominated EBL. Similarly, if adherence with EBL was even 1\%, then EBL + M dominated MED alone. However, if adherence with a 2-wk cycle of medications, adherence with a single EBL or EGD session, and adherence with a single ultrasound surveillance were all set equal, then TIPS was the optimal strategy if adherence with each of these interventions was simultaneously less than $12 \%$. If adherence with either MED or EBL was higher, than TIPS was no longer optimal.

The choice of optimal strategy was not sensitive to changes in any of the other variables in the model. Specifically, EBL + $M$ was the optimal strategy regardless of the baseline risk of $\mathrm{VH}$, the mortality rate associated with $\mathrm{VH}$, or the probability of TIPS dysfunction.

TWO-WAY SENSITIVITY ANALYSES. Two-way sensitivity analyses were performed to see if the optimal strategy could be altered. Because important variables in the oneway sensitivity analyses included the OR of VH with EBL compared to MED, and the OR with EBL + M compared to EBL alone, we performed a two-way sensitivity analysis of these two variables on cost-effectiveness (Fig. 3A). The optimal strategy depended on the combination of these variables. As already mentioned, in the base-case scenario EBL + $\mathrm{M}$ was optimal in terms of cost-effectiveness (the square

Table 3. One-way Sensitivity Analyses: Changes in Optimal Strategy

\begin{tabular}{|c|c|c|c|}
\hline Variables & Base-Case (range) & Threshold & Optimal $^{*}$ \\
\hline Decrement in quality of life due to medications & $2 \%(0-50 \%)$ & $>4 \%$ & EBL \\
\hline Odds of VH with EBL compared to MED & $0.45(0.24-2.61)$ & $>1.73 x$ & MED \\
\hline Odds of VH with EBL compared to EBL $+\mathrm{M}$ & $2.84(1-3.45)$ & $<1.47 \mathrm{x}$ & EBL \\
\hline Adherence rate to all ${ }^{\S}$ & $100 \%(0-100 \%)$ & $<12 \%$ & TIPS \\
\hline
\end{tabular}

$\mathrm{EBL}=$ endoscopic band ligation, $\mathrm{EBL}+\mathrm{M}=$ combination $\mathrm{EBL}$ plus medical therapy, $\mathrm{MED}=$ medical therapy, $\mathrm{QALY}=$ quality-adjusted life-years, $\mathrm{VH}=$ variceal hemorrhage. *The optimal strategy was defined as the one that offered the most QALYs at a cost of no more than \$50,000 per each additional QALY compared to the next most effective strategy. In all of the other one-way sensitivity analyses, the optimal strategy did not change from EBL $+\mathrm{M}$.

$\S$ In this analysis, the adherence rates for medications, EBL, EGD and ultrasound were all set equal. Note that when adherence with each strategy was modeled independently of each other, EBL + M was always the optimal strategy. 


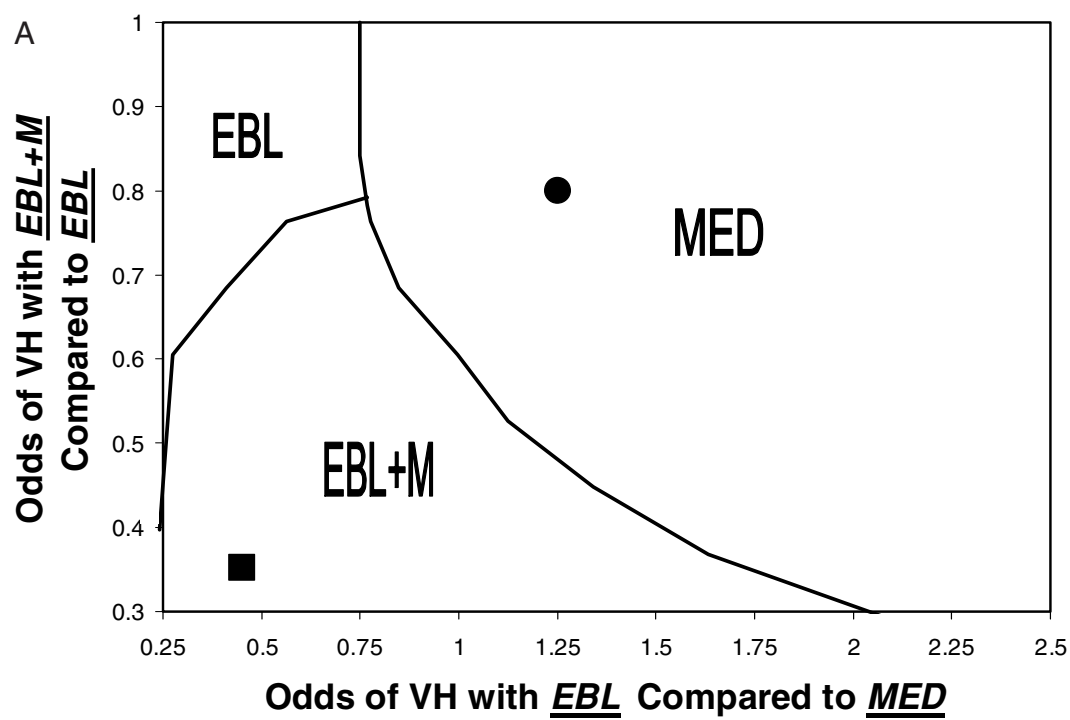

$\mathrm{EBL}=$ endoscopic band ligation, $\mathrm{EBL}+\mathrm{M}=$ combination $\mathrm{EBL}$ plus medical therapy, $\mathrm{MED}=$ medical therapy, $\mathrm{VH}=$ variceal hemorrhage

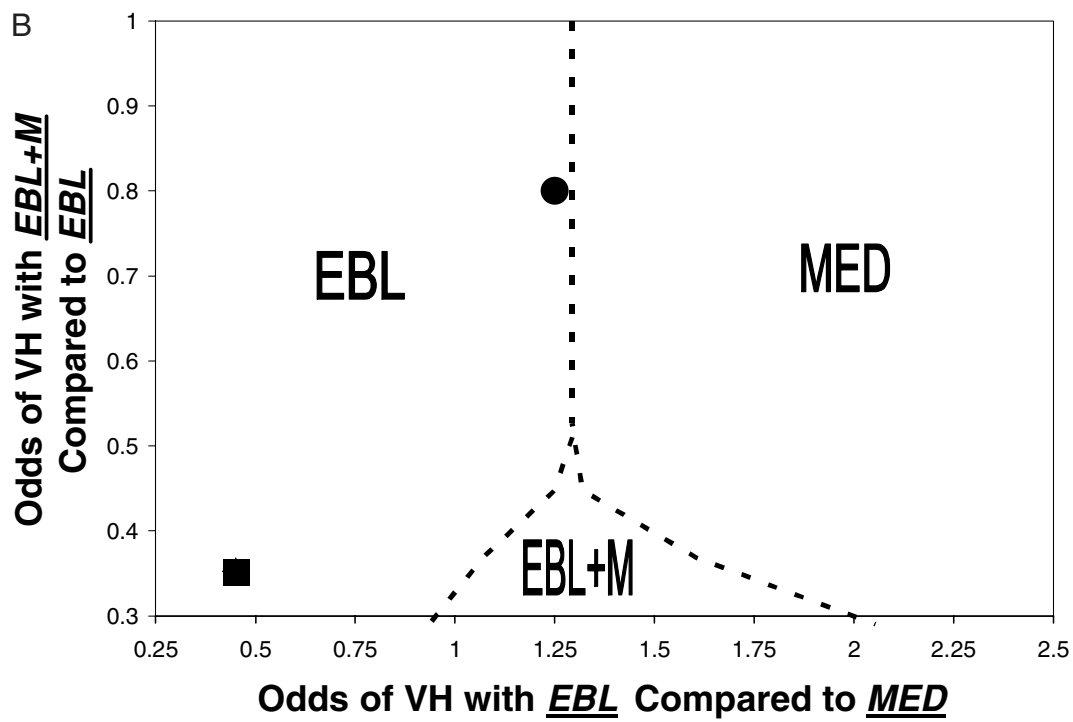

$\mathrm{EBL}=$ endoscopic band ligation, $\mathrm{EBL}+\mathrm{M}=$ combination $\mathrm{EBL}$ plus medical therapy, $\mathrm{MED}=$ medical therapy, $\mathrm{VH}=$ variceal hemorrhage

Figure 3. (A) Effect of comparative efficacies of strategies on cost-effectiveness: two-way sensitivity analysis of odds of VH with EBL compared to MED, and odds of VH with EBL + M compared to EBL alone. The $x$-axis is the OR of VH with EBL compared to MED, and contains the entire range of values in the sensitivity analysis. At a value of 1 , the two are equivalent in terms of efficacy of prevention of VH, but not necessarily cost-effectiveness in terms of QALYs. MED is more efficacious in preventing VH toward the right and EBL toward the left. The $y$-axis is the OR of VH with EBL + M compared to EBL alone, and contains the entire range of values in the sensitivity analysis. Adding MED to EBL is more efficacious in preventing VH toward the bottom. The strategies label the domain of combination of efficacies in which the strategy was optimal in terms of cost-effectiveness; the lines represent the frontiers between domains. The base case (square) resulted in an optimal strategy of EBL + M, while an example (circle) where OR VH EBL: M was 1.25 and OR VH EBL + M: EBL was 0.8 resulted in an optimal strategy of MED. In this analysis, all other variables were at their base-case values (i.e., utility toll of medications was $2 \%$, and adherence with medications was $100 \%)$. $(B)$ Effect of medication utility toll on cost-effectiveness: two-way sensitivity analysis of OR VH EBL: MED and OR VH EBL + M: EBL at 10\% utility toll for medications. The only difference in this analysis from Figure $3 \mathrm{~A}$ is that in this analysis, the decrement in quality of life associated with medications was changed from $2 \%$ to $10 \%$. This increased the domain in which EBL was optimal such that EBL was the optimal strategy for both the base case (square) and the example (circle). ( $C$ ) Effect of nonadherence with medical therapy on cost-effectiveness: two-way sensitivity analysis of OR VH EBL: MED and OR VH EBL + M: EBL at 50\% adherence with medications. The only difference between this analysis and Figure 3A is that adherence with medications was changed from $100 \%$ to $50 \%$. This decreased the domain in which MED was optimal, and increased the domain in which EBL $+\mathrm{M}$ was optimal such that EBL $+\mathrm{M}$ was the optimal strategy for both the base case (square) and the example (circle). 


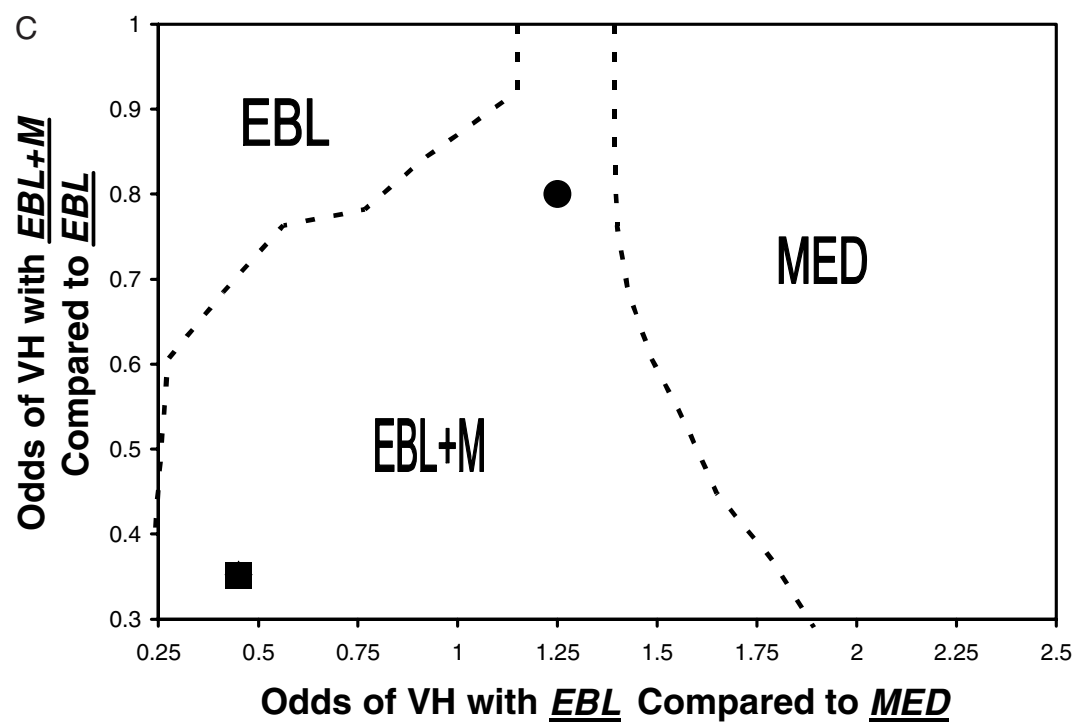

$\mathrm{EBL}=$ endoscopic band ligation, $\mathrm{EBL}+\mathrm{M}=$ combination EBL plus medical therapy, $\mathrm{MED}=$ medical therapy, $\mathrm{VH}=$ variceal hemorrhage

Figure 3. (Continued)

representing the base case in the figure falls in the domain where EBL $+M$ is optimal). For a different example, if the odds of VH with EBL was 1.25 times the odds with MED, and the odds of VH with EBL $+\mathrm{M}$ was 0.8 times the odds with EBL alone, then MED was the optimal strategy (the circle representing this example in the figure falls in the domain where MED is optimal). The frontiers between the cost-effective domains for each strategy in this two-way sensitivity analysis are themselves sensitive to changes in two other important variables, the utility toll of medications (i.e., the decrease in quality of life due to side effects of medications) and the adherence rate with medications or EBL. If the utility toll of medications was $10 \%$ rather than the $2 \%$ in the base case, the domain in which EBL was the optimal cost-effective strategy increased (Fig. 3B); in that situation EBL was the optimal strategy for the example detailed above, rather than MED. Alternatively, if adherence with medications was $50 \%$, the domain where MED is the most cost-effective strategy became smaller while that of EBL $+\mathrm{M}$ became larger (Fig. 3C). In fact, in that situation, EBL $+M$ was the optimal strategy for the example case rather than MED.

\section{MONTE CARLO ANALYSIS (MULTIWAY SENSITIVITY} ANALYSIS). A Monte Carlo analysis examines the robustness of a model by varying multiple variables simultaneously. The utility tolls and adherence rates were kept constant at the base-case values because empiric data are needed to program their distributions, and no such data exist for those variables. A total of 10,000 combinations of randomly chosen values for the remaining 41 variables were analyzed (Table 4). The average QALYs and costs for each of the strategies redemonstrated that EBL $+\mathrm{M}$ was the optimal strategy on average. However, EBL + M was the optimally cost-effective strategy
Table 4. Primary Monte Carlo Analysis

\begin{tabular}{lcccc}
\hline & \multirow{2}{*}{ Mean } & Mean Cost & \multicolumn{2}{c}{$\%$ Optimal* $^{*}$} \\
\cline { 4 - 5 } Strategies & QALYs & $(\$ 1,000 \mathrm{~s})$ & $\mathrm{WTP}=\$ 50 \mathrm{~K}$ & $\mathrm{WTP}=\$ 100 \mathrm{~K}$ \\
\hline OBS & 1.36 & 22.8 & $0 \%$ & $0 \%$ \\
MED & 1.49 & 16.8 & $19 \%$ & $12 \%$ \\
TIPS & 1.52 & 33.4 & $0 \%$ & $0 \%$ \\
EBL & 1.54 & 19.3 & $19 \%$ & $27 \%$ \\
EBL + M & 1.56 & 17.2 & $62 \%$ & $61 \%$ \\
\hline
\end{tabular}

$\mathrm{EBL}=$ endoscopic band ligation, $\mathrm{EBL}+\mathrm{M}=$ combination $\mathrm{EBL}$ plus medical therapy, $\mathrm{MED}=$ medical therapy, OBS $=$ observation, $\mathrm{QALY}=$ quality-adjusted life-year, TIPS $=$ transjugular intrahepatic portosystemic shunt, $\mathrm{WTP}=$ willingness to pay.

$* \%$ Optimal is the percentage of combinations that result in that strategy being the optimal one defined as that which yields the most QALYs at an ICER no greater than the WTP per each QALY gained when compared to the next most effective strategy.

in only $62 \%$ of combinations; nonetheless, neither observation nor TIPS was the optimal strategy more than $1 \%$ of the time, even if the third-party payer was willing to pay $\$ 100,000$ per QALY. In order to verify whether the four variables identified in the one-way sensitivity analyses accounted for the variance in optimal strategies demonstrated in the Monte Carlo analysis, the Monte Carlo was repeated while holding all four of those variables constant at their base-case values, i.e., in addition to adherence rates and the utility tolls being held constant, the OR of VH with EBL compared to MED, and the OR of VH with EBL + M compared to EBL were held constant (Table 5). Indeed, when those four variables were held constant, EBL + M was the optimal strategy in $95 \%$ of the combinations.

\section{DISCUSSION}

We created a Markov process model of secondary prophylaxis for $\mathrm{VH}$, and performed a cost-utility analysis. The base-case 
Table 5. Monte Carlo Analysis of 39 Selected Variables

\begin{tabular}{lcccc}
\hline & \multirow{2}{*}{ Mean } & Mean Cost & \multicolumn{2}{c}{$\%$ Optimal* $^{*}$} \\
\cline { 4 - 5 } Strategies & QALYs & $(\$ 1,000 \mathrm{~s})$ & WTP $=\$ 50 \mathrm{~K}$ & WTP = \$100K \\
\hline OBS & 1.36 & 22.7 & $0 \%$ & $0 \%$ \\
MED & 1.48 & 16.8 & $4 \%$ & $0 \%$ \\
TIPS & 1.52 & 33.0 & $0 \%$ & $0 \%$ \\
EBL & 1.57 & 17.9 & $1 \%$ & $6 \%$ \\
EBL + M & 1.58 & 16.3 & $95 \%$ & $94 \%$ \\
\hline
\end{tabular}

$\mathrm{EBL}=$ endoscopic band ligation, $\mathrm{EBL}+\mathrm{M}=$ combination $\mathrm{EBL}$ plus medical therapy, $\mathrm{MED}=$ medical therapy, OBS = observation, $\mathrm{QALY}=$ quality-adjusted life-year, TIPS $=$ transjugular intrahepatic portosystemic shunt, WTP $=$ willingness to pay.

$* \%$ Optimal is the percentage of combinations that result in that strategy being the optimal one defined as that which produces the most QALYs at an ICER no greater than the WTP per each QALY gained when compared to the next most effective strategy.

In this analysis, OR VH EBL:M and OR VH EBL + M:EBL were held constant, in addition to adherence rates and utility tolls.

analysis showed that strategies of medical therapy, band ligation, or combined medication and band ligation all dominated the strategy of observation, meaning they were both more effective and cost saving. It is quite unusual to find interventions in medical practice that dominate the strategy of OBS - benefits almost always cost money (33). Additionally, the study demonstrates the potential importance of the decrement in quality of life imposed by medications, the potential benefits of a strategy of combined EBL and medical therapy, and the inadequacies of TIPS.

While EBL + M dominated both MED alone and EBL alone in the base-case analysis, the Monte Carlo analysis found $E B L+M$ to be the optimal strategy in only $61 \%$ of cases, revealing significant uncertainty in which of those three it is optimal. Therefore, the result of the base-case analysis is not robust enough to recommend that all patients receive combined EBL and medications as secondary prophylaxis for $\mathrm{VH}$; further empirical studies are needed in order to improve the robustness of the model. As shown in the one-way and two-way sensitivity analyses, the values of only a few important variables need to be known more confidently. The ORs of VH with EBL compared to MED, and of VH with $\mathrm{EBL}+\mathrm{M}$ compared to EBL describe the relative efficacy of the three strategies. There are few empiric data regarding the exact values for those two variables. Only three randomized controlled trials to date have compared EBL and medical therapy. The first, by Villanueva et al. concluded that combined therapy with nadolol and isosorbide mononitrate, titrated to the invasively measured hepatic venous pressure gradient (HVPG), prevented more VH than EBL did (10). The study by Patch et al. purported similar efficacy of both propranolol plus isosorbide mononitrate titrated to the HVPG and EBL, finding a relative hazard for rebleeding with EBL versus MED of 1.41 (95\% CI, 0.78-2.55) (12). However, the power calculation for that study called for 193 patients, but the study was terminated after the enrollment of only 104 subjects due to inability to recruit enough subjects in a timely fashion. The study by Lo et al. found that EBL was more efficacious than nadolol and isosorbide mononitrate titrated to noninvasive clinical parameters, with a relative risk of
0.45 (95\% CI, 0.24-0.85) (11). Because meta-analyses have found that sclerotherapy is more efficacious than propranolol, and that band ligation is more efficacious than sclerotherapy, we believe Lo's results to be the most plausible $(8,9)$. However, the aggressive titration of combined beta-blockade and nitrates using the HVPG may well improve the efficacy of medical prophylaxis compared to EBL considerably. Further studies comparing these strategies are certainly warranted.

This study shows that the efficacy of medical therapy in preventing VH can be offset to a significant degree by even a slight chronic decrement in the quality of life caused by the medications. Beta-blockers can cause adverse effects that nonetheless are tolerated in order to allow for continuation of therapy. In cardiovascular trials, fatigue and sexual dysfunction are reported by significantly more patients taking betablockers than placebo (absolute risk increase of 3.0\% and $4.2 \%$, respectively), and patients taking nonselective betablockers appear to be at an even higher risk for fatigue than those taking selective beta-blockers (34). It is not known what effect beta-blockers have on the utility of patients with decompensated cirrhosis; however, we found that even a small toll of $4 \%$ on the utility can make EBL alone favored over $\mathrm{EBL}+\mathrm{M}$ despite the improved efficacy of the combined strategies for $\mathrm{VH}$ prevention. In practice, this might mean that a patient who notes any adverse effect of the medications whatsoever may be better served by a different strategy. Future studies should address this important question.

We found that combined EBL $+\mathrm{M}$ has the potential to be the optimal strategy for secondary prophylaxis. We could find only one published study comparing combined band ligation and medications to either therapy alone, so the results of the base-case analysis are certainly not robust (14). That one study found that the odds of VH with EBL alone were almost 3 times the odds with EBL $+\mathrm{M}(p=0.001)$. Importantly, the model demonstrates that EBL $+\mathrm{M}$ is a very good strategy in situations with less-than-perfect adherence. This is analogous to wearing both a belt and suspenders to hold up pants. Combining strategies offers slightly extra benefit and is not costly; more importantly, if either process breaks down, the other alone is still a cost-effective strategy. The process of incorporating redundancy in critical systems to improve reliability has been illustrated in previous studies $(35,36)$. As shown in Figures $3 \mathrm{~A}$ and $\mathrm{C}$, in many scenarios of perfect adherence where medications alone was the optimal strategy, $\mathrm{EBL}+\mathrm{M}$ became the optimal strategy if adherence with medications was changed to $50 \%$ despite the very good efficacy and costs of medical therapy. A corresponding argument can be made regarding adherence to EBL. Additional controlled trials are needed to compare the efficacy of combined medication and band ligation with either therapy alone; in the meantime, the results of the base-case analysis depend entirely on the one existing trial, and hence the result is uncertain as demonstrated by the Monte Carlo analysis.

To our knowledge, there are no studies examining adherence rates to secondary prophylaxis of $\mathrm{VH}$ in clinical practice that use outcomes applicable to this Markov process. A 
prospective cohort study of propranolol found that 38\% of subjects had poor adherence as defined as either ever missing a dose or stopping therapy entirely; only $45 \%$ of patients with poor adherence were free from rebleeding at $2 \mathrm{yr}$ versus $71 \%$ of patients with good adherence $(p=0.01)(37)$. Since it was a prospective study in which subjects gave informed consent, nonadherence in actual practice could be considerably higher. No real-world studies documenting adherence with band ligation or TIPS have been published. In short, we have found that adherence can have an important effect on the effectiveness of prophylaxis, that combined $\mathrm{EBL}+\mathrm{M}$ is very resilient to poor adherence, and that there are few applicable data regarding adherence in actual practice pertaining to this issue.

This study demonstrated that TIPS was relatively ineffective in producing QALYs despite its very good efficacy in preventing VH. Meta-analyses have demonstrated the better efficacy of TIPS in preventing rebleeding from esophageal varices compared to endoscopic therapy, but have not been able to demonstrate a survival benefit $(13,38,39)$. It has been suggested that this lack of a survival benefit may be due to a type II error (38). A previous study of VH has shown that multistate Markov models may be more accurate in predicting survival than calculations of the marginal survival distribution in trials (40). Our study reconfirmed that despite lower rates of VH with TIPS compared to EBL, the 3 -yr survival rates were identical. Looking at Table 2, it is clear that with each strategy that is successively more efficacious in preventing $\mathrm{VH}$, there are diminishing incremental gains because there are fewer and fewer VH left to prevent; for instance, MED prevents $0.79 \mathrm{VH}$ compared to OBS, but TIPS only prevents an additional $0.13 \mathrm{VH}$ compared to EBL. This diminishing incremental gain is part of the reason why meta-analyses have shown that medical prophylaxis improves survival compared to observation, but have not been able to show a similar survival improvement with TIPS compared to endoscopic therapy $(1,41,42)$. In addition, the absence of a survival effect is likely due to the small, but significant rates of mortal complications and technical failure with TIPS placement (1.5\% and 3.4\%, respectively in the base case) factors that are unlikely to be dramatically improved upon. The high rates of HE with TIPS, high rates of TIPS dysfunction, and the associated costs of surveillance and TIPS revision certainly are substantial; however, even minimizing these effects did not make TIPS optimal. Furthermore, any improvements in TIPS technology with regard to the rate of dysfunction may necessarily also increase the rate of $\mathrm{HE}$ and worsen hepatic function (39). All of this evidence suggests that any improvements in TIPS technology that decrease the rate of TIPS dysfunction will translate into relatively little improvement in QALYs compared to other prophylactic strategies, and may actually diminish QALYs. Based on this study, TIPS would appear to have no role in secondary prophylaxis of VH. Notably, however, the study did not address the management of uncontrolled VH; TIPS may very well have a useful role in that scenario.
We were surprised to find that TIPS was neither very effective in terms of QALYs, nor cost-effective, since the only previously published decision analysis of secondary prophylaxis for $\mathrm{VH}$ concluded it to be both, in terms of VH prevented (16). The study by Russo et al. was a cost-effectiveness analysis comparing the strategies of TIPS, EBL $+\mathrm{M}$, and sclerotherapy plus medications with a time horizon of $1 \mathrm{yr}$ That model assumed a $20 \%$ rate of crossover from other therapies to TIPS, and involved 27 variables including a higher HE rate with TIPS and a $40 \%$ rate of TIPS dysfunction requiring TIPS revision. They concluded that TIPS was cost-effective with an ICER of $\$ 12,660$ per additional VH prevented compared to EBL $+\mathrm{M}$, but did not provide the cost in terms of QALYs. In a post hoc analysis, we used their base-case values and time horizon in our model, and found that the ICER for TIPS compared to EBL + M was $\$ 48,187$ per additional VH prevented, but at a cost of over $\$ 4$ million per additional QALY. The advantage of a cost-utility analysis is that the result can be compared to economies of management of other disease states such as breast cancer screening or childhood immunizations. Finally, our study differed from the study by Russo et al. by including a strategy of observation or donothing. While such a strategy is rarely pursued in clinical practice intentionally, it offers an important reference point. For instance, we found that MED, EBL, and EBL + M all dominated the strategy of observation, a finding very relevant to payers.

There were a number of limitations to our study. One was the exclusion of the strategy of medications titrated to HVPG. We performed a sensitivity analysis simulating that specific scenario by adjusting the relative efficacies of observation, MED, and EBL in preventing VH (data not shown). In that scenario, medications appeared to be the optimal strategy, but the analysis did not account for the costs and complications of HVPG measurements. Similarly, the model excluded the option of liver transplantation or crossover to other strategies for failed cases; however, the available literature does not examine the prophylactic strategies in those patient populations per se.

Another limitation was that the time horizon of this model was only 3 yr. Ideally, a cost-utility analysis ought to follow each patient until death, thus comparing the quality-adjusted time offered by each strategy over the entire remaining life. We did extend our time horizon to $15 \mathrm{yr}$, and still found EBL + $M$ the optimal strategy in the base case (data not shown), but in order to perform the analysis properly with a horizon of death, we would have needed actuarial life-tables for decompensated cirrhosis in the absence of $\mathrm{VH}$, longer-term data on the natural history of $\mathrm{VH}$, and longer-term data on the efficacies, complications, and necessary surveillance of the various strategies. To date, the published literature does not furnish those details, so we could not use such a time horizon. Furthermore, Markov chains assume that the transition rates stay constant over time, which may not be the case with $\mathrm{VH}$ and its prophylactic strategies even over the short time horizon of $3 \mathrm{yr}$. 
The foremost limitation was the uncertainty in the conclusion of which strategy was optimal. The Monte Carlo analysis demonstrated that $\mathrm{EBL}+\mathrm{M}$ was only optimal in $62 \%$ of cases. We showed that the substantial variance in the optimal strategy was explained by the uncertainty regarding the relative efficacy of MED, EBL, and EBL $+\mathrm{M}$ in preventing $\mathrm{VH}$, the decrement in quality of life due to medications and adherence. In turn, the true values of those variables themselves have considerable uncertainty in the published literature, a limitation of most decision analyses. While this study did not determine which of the three strategies should be the standard of care, it did identify which variables are important for further research. As mentioned above, there has been only one study comparing the efficacy of combination medication and band ligation to either alone, and no studies of the effect medications have on quality of life in these patients, and no relevant studies of adherence rates in this population for these strategies. The true values of many of the other variables may also be uncertain, but precisely determining them is not necessary to resolve this question.

In summary, our study demonstrated the cost-effectiveness of secondary prophylaxis of $\mathrm{VH}$ with either medications, band ligation, or their combination compared to observation or TIPS. Combined medications and band ligation is likely the optimal strategy, in part because it is resilient to poor adherence. The results are not robust, so further research is needed to determine the relative efficacies of medications, band ligation, and their combination in preventing $\mathrm{VH}$, as well as to determine the effect the medications have on health state utilities, and the rate of adherence with the strategies in actual practice.

\section{APPENDIX A: MODEL STRUCTURE}

In order to account for so many variables such as complications and adherence, the model was necessarily complex, represented by over 1,300 branches. However, in order to keep the model relatively simple, a number of assumptions were introduced based on the model's geometry or structure. These assumptions are unlikely to affect which strategy is preferred, but may affect the exact ICER.

\section{Mortality From Variceal Hemorrhage}

Death from VH was assumed to take place within $2 \mathrm{wk}$ from the onset of hemorrhage. This risk was based on the published 30-d mortality, and the risk of death after $2 \mathrm{wk}$ was assumed to return to baseline. The risk was assumed to be independent of the strategy for prophylaxis (43).

\section{Complementary Probabilities}

The risk of developing encephalopathy was modeled as complementary to the risk of $\mathrm{VH}$ and the risk of death without VH. Therefore, patients could not develop VH and persistent $\mathrm{HE}$ in the same cycle.

\section{Encephalopathy During EBL}

Due the restrictions of utilizing tunnel states, patients could not develop HE during a series of EBL. After completion of the series, or nonadherence with the series, the mean cumulative risk of having had developed HE during those cycles, and its associated costs were applied.

\section{Interaction of Surveillance Intervals with Encephalopathy or Adherence}

Due to the restrictions of utilizing tunnel states, two artifacts were introduced. If patients developed encephalopathy, then the timer to either the surveillance endoscopy or surveillance ultrasound was reset. In the EBL $+\mathrm{M}$ arm, a similar artifact occurred if patients changed their adherence with medication. This artifact was not an issue in the base-case scenario because it assumed perfect adherence. The only way to avoid these artifacts of tunnel states entirely would be to perform only a Monte Carlo simulation using tracker variables; cohort analysis, which present results conventionally and allows for one-way sensitivity analyses, cannot be performed without introducing these artifacts.

\section{Simplifications in the EBL + M Strategy}

In the EBL + M strategy, adherence with either EBL or medications was modeled independently; therefore, that arm of the model involved the most complexity, and a few simplifications were assumed. We assumed that the rate of recurrence of varices after EBL in patients who were adherent with medical therapy was identical to that of patients who undergo EBL alone. In patients who adhered to initial EBL, but were nonadherent with surveillance endoscopy and had undetected recurrent varices despite adhering to medical therapy, the observation rate of $\mathrm{VH}$ was assumed, but the patients still accumulated the costs and utility tolls of medical therapy. Among patients who had undetected varices while nonadherent with both medications and surveillance endoscopy, their course was determined by their adherence with medications at the next surveillance interval. If these patients adhered with medications at that time, then they were assumed to have the same risk of recurrent varices as patients in the EBL alone strategy. However, if they were still nonadherent with medications at the time of surveillance endoscopy, but adhered to the endoscopy, they were assumed to still have the varices and so automatically began a series of band ligation.

\section{APPENDIX B: TRANSITION PROBABILITIES}

\section{Rates of Variceal Hemorrhage}

The ORs for VH were based in large part on meta-analyses of the respective strategies. To confirm that these ORs represent the true efficacy, ratios were additionally derived in alternative ways in select cases. For instance, the OR of VH with beta-blockers plus nitrates compared to observation was derived, and was found to lie within the published range of OR for beta-blockers alone compared to observation (23). 
Similarly, the OR for VH with EBL compared to medications was derived by multiplying the $\mathrm{OR}$ for $\mathrm{VH}$ for $\mathrm{EBL}$ compared to sclerotherapy, by the OR for $\mathrm{VH}$ for sclerotherapy compared to beta-blockers; these latter two ORs have been determined by meta-analyses $(8,9)$. This resulted in an OR for VH with EBL compared to medications of 0.235 , just below the lower limit used in the sensitivity analysis. Finally, rates of VH with TIPS were derived from both the OR in meta-analyses of TIPS versus endoscopic therapy, and from the OR in the only study of TIPS versus medical therapy; these rates were found to be comparable (44).

For the OR of VH in EBL + M compared to EBL alone, the lower limit was taken to be identical to that found for the $\mathrm{OR}$ of $\mathrm{VH}$ with medication compared to observation, and the upper limit of the sensitivity analysis was set at 1 (meaning that adding medication adds no additional benefit).

\section{Mortality in Absence of $\mathrm{VH}$}

The base-case rate of mortality without a $\mathrm{VH}$ was derived from a meta-analysis of controlled trials (1). The lower limit was taken from the United States vital statistics for the average 50-yr-old Caucasian American man (45). The upper limit assumed the total risk of death associated with a population of patients awaiting liver transplantation (46).

\section{Number of Band Ligation Procedures}

The number of sessions required to complete band ligation was modeled as normally distributed using the mean, and the mean of the standard deviations from published trials. This probability distribution was used in each analysis, and was not varied in a sensitivity analysis.

\section{APPENDIX C: COSTS}

Hypothetical pseudo-bills for each Markov state or transition state were created as follows. The annual care of cirrhosis without VH or HE included three outpatient visits with lab work; one-third of patients were hypothesized to be taking furosemide and aldactone for ascites. The additional annual care for HE included lactulose twice a day, two additional outpatient visits, and three 4-d hospitalizations that included initial work-ups for infection (chest radiograph, urinalysis and culture, blood culture, and paracentesis with fluid studies), and antibiotics. VH included $2 \mathrm{~d}$ of critical care, $4 \mathrm{~d}$ of general ward care, an upper endoscopy with band ligation, $72 \mathrm{~h}$ of octreotide infusion, central venous catheter placement, transfusion of five units of packed red blood cells, and intravenous antibiotics $(47,48)$. Medical therapy annual costs were for an average dose of propranolol $40 \mathrm{mg}$ twice daily, and one additional outpatient visit per year to titrate the dose. Complications of band ligation were modeled for the diagnosis and treatment of a bleeding esophageal ulcer. The cost of complications of upper endoscopy without band ligation was modeled on an esophageal perforation treated conservatively. The cost of TIPS included a postprocedure ultrasound with Doppler, and a 6\% rate of acute occlusion necessitating thrombolysis, an additional hospital day, and a repeat ultrasound (49). The cost of a complication from TIPS was based on conservative management of bleeding, including hospitalization and a computed tomogram of the abdomen and pelvis. A complication from hepatic venography was modeled similarly.

\section{APPENDIX D: MONTE CARLO ANALYSIS}

In the Monte Carlo analysis, random values for each variable were selected simultaneously for 10,000 independent runs of the model. The distribution and mode of each variable was prespecified. Adherence rates and utility tolls were not varied in the Monte Carlo analysis because their base-case values were chosen $a d$ hoc by author consensus, and because the model was found to be sensitive to their values in the one-way and two-way sensitivity analyses. Even defining a distribution of those variables would have necessarily biased the result of the analysis. For instance, if the utility toll for medications was defined as normally distributed with a mean of $2 \%$ and $95 \%$ confidence interval of $0-4 \%$, the analysis would be biased in favor of medications; if it were defined as a uniform distribution with a range of $0-10 \%$, the analysis would be biased against medications. Because we had no empiric means with which to define the distributions of these variables, we specifically chose to set them at their base-case values.

The Monte Carlo analysis was repeated while holding constant the variables found to be important in the one-way sensitivity analysis. If those variables were indeed the cause of much of the uncertainty in the result, then the uncertainty should diminish significantly if they were held constant.

\section{ACKNOWLEDGMENTS}

Dr. Rubenstein is funded by a Training Grant for Research in Gastroenterology from the National Institutes of Health (2 T32 DK07367). Dr. Inadomi is funded by an American College of Gastroenterology Faculty Development Award and a grant from the Department of Veterans Affairs, Veterans Health Administration, Health Services Research and Development Service (IIR 99-238-2). Dr. Eisen is funded by a National Institutes of Health (NIDDK) grant UO1-DK5713201 . None of the funding agencies influenced the design, conduct, or reporting of this study.

Reprint requests and correspondence: Joel H. Rubenstein, M.D., Division of Gastroenterology, University of Michigan Health System, 3912 Taubman Center, Ann Arbor, MI 48109-0362.

Received September 11, 2003; accepted November 26, 2003.

\section{REFERENCES}

1. Bernard B, Lebrec D, Mathurin P, et al. Beta-adrenergic antagonists in the prevention of gastrointestinal rebleeding in 
patients with cirrhosis: A meta-analysis. Hepatology 1997; 25:63-70.

2. Garden OJ, Mills PR, Birnie GG, et al. Propranolol in the prevention of recurrent variceal hemorrhage in cirrhotic patients: A controlled trial. Gastroenterology 1990;98:18590.

3. Graham DY, Smith JL. The course of patients after variceal hemorrhage. Gastroenterology 1981;80:800-9.

4. D’Amico G, Luca A. Natural history. Clinicalhaemodynamic correlations. Prediction of the risk of bleeding. Bailliere's Clin Gastroenterol 1997;11:243-55.

5. El-Serag HB, Everhart JE. Improved survival after variceal hemorrhage over an 11-year period in the Department of Veterans Affairs. Am J Gastroenterol 2000;95:3566-73.

6. Chalasani N, Kahi C, Francois F, et al. Improved patient survival after acute variceal bleeding: A multicenter, cohort study. Am J Gastroenterol 2003;98:653-9.

7. Grace ND. Diagnosis and treatment of gastrointestinal bleeding secondary to portal hypertension. Am J Gastroenterol 1997;92:1081-91.

8. Bernard B, Lebrec D, Mathurin P, et al. Propranolol and sclerotherapy in the prevention of gastrointestinal rebleeding in patients with cirrhosis: A meta-analysis. J Hepatol 1997;26:312-24.

9. Laine L, Cook D. Endoscopic ligation compared with sclerotherapy for treatment of esophageal variceal bleeding. A meta-analysis. Ann Intern Med 1995;123:280-7.

10. Villanueva C, Minana J, Ortiz J, et al. Endoscopic ligation compared with combined treatment with nadolol and isosorbide mononitrate to prevent recurrent variceal bleeding. $\mathrm{N}$ Engl J Med 2001;345:647-55.

11. Lo G-H, Chen W-C, Chen M-H, et al. Banding ligation versus nadolol and isosorbide mononitrate for the prevention of esophageal variceal rebleeding. Gastroenterology 2002;123:728-34.

12. Patch D, Sabin CA, Goulis J, et al. A randomized, controlled trial of medical therapy versus endoscopic ligation for the prevention of variceal rebleeding in patients with cirrhosis. Gastroenterology 2002;123:1013-9.

13. Papatheodoridis GV, Goulis J, Leandro G, et al. Transjugular intrahepatic portosystemic shunt compared with endoscopic treatment for prevention of variceal rebleeding: A meta-analysis. Hepatology 1999;30:612-22.

14. Lo GH, Lai KH, Cheng JS, et al. Endoscopic variceal ligation plus nadolol and sucralfate compared with ligation alone for the prevention of variceal rebleeding: A prospective, randomized trial. Hepatology 2000;32:461-5.

15. Pomier-Layrargues G, Villeneuve JP, Deschenes M, et al. Transjugular intrahepatic portosystemic shunt (TIPS) versus endoscopic variceal ligation in the prevention of variceal rebleeding in patients with cirrhosis: A randomised trial. Gut 2001;48:390-6.

16. Russo MW, Zacks SL, Sandler RS, et al. Cost-effectiveness analysis of transjugular intrahepatic portosystemic shunt (TIPS) versus endoscopic therapy for the prevention of recurrent esophageal variceal bleeding. Hepatology 2000;31:358-63.

17. Gatta A, Merkel C, Sacerdoti D, et al. Nadolol for prevention of variceal rebleeding in cirrhosis: A controlled clinical trial. Digestion 1987;37:22-8.

18. Rossi V, Cales P, Burtin P, et al. Prevention of recurrent variceal bleeding in alcoholic cirrhotic patients: Prospective controlled trial of propranolol and sclerotherapy. J Hepatol 1991;12:283-9.

19. Lebrec D, Poynard T, Hillon P, et al. Propranolol for the prevention of recurrent gastrointestinal bleeding in patients with cirrhosis. N Engl J Med 1981;305:1371-4.
20. Burroughs AK, Jenkins WJ, Sherlock S, et al. Controlled trial of propranolol for the prevention of recurrent variceal hemorrhage in patients with cirrhosis. $\mathrm{N}$ Engl J Med 1983;309:1539-42.

21. Colombo M, De Franchis R, Tommasini M, et al. Betablockade prevents recurrent gastrointestinal bleeding in well-compensated patients with alcoholic cirrhosis: A multicenter randomized controlled trial. Hepatology 1989;9:4338.

22. Villeneuve J-P, Pomier-Layrargues G, Infante-Rivard C, et al. Propranolol for the prevention of recurrent variceal hemorrhage: A controlled trial. Hepatology 1986;6:123943.

23. Gournay J, Masliah C, Martin T, et al. Isosorbide mononitrate and propranolol compared with propranolol alone for the prevention of variceal rebleeding. Hepatology 2000;31:1239-45.

24. Jalan R, Forrest EH, Stanley AJ, et al. A randomized trial comparing transjugular intrahepatic portosystemic stent-shunt with variceal band ligation in the prevention of rebleeding from esophageal varices. Hepatology 1997;26:1115-22.

25. Sauer P, Theilmann L, Stremmel W, et al. Transjugular intrahepatic portosystemic stent shunt versus sclerotherapy plus propranolol for variceal rebleeding. Gastroenterology 1997;113:1623-31.

26. Gulberg V, Schepke M, Geigenberger G, et al. Transjugular intrahepatic portosystemic shunting is not superior to endoscopic variceal band ligation for prevention of variceal rebleeding in cirrhotic patients: A randomized, controlled trial. Scand J Gastroenterol 2002;37:338-43.

27. Gold MR, Siegel JE, Russell LB, et al. Cost-effectiveness in health and medicine. New York: Oxford University Press, 1996.

28. Company ME. Drug topics red book. Montvale, NJ: Medical Economics Company, 2002.

29. Younossi ZM, Boparai N, McCormick M, et al. Assessment of utilities and health-related quality of life in patients with chronic liver disease. Am J Gastroenterol 2001;96:579 83.

30. Chong CAKY, Gulamhussein A, Heathcote EJ, et al. Healthstate utilities and quality of life in hepatitis $\mathrm{C}$ patients. Am J Gastroenterol 2003;98:630-8.

31. Bennett WG, Inoue Y, Beck JR, et al. Estimates of the cost-effectiveness of a single course of interferon-alpha2b in patients with histologically mild chronic Hepatitis C. Ann Intern Med 1997;127:855-65.

32. Wong JB, Bennett WG, Koff RS, et al. Pretreatment evaluation of chronic Hepatitis C: Risks, benefits, and costs. JAMA 1998;280:2088-93.

33. Chapman RH, Stone PW, Sandberg EA, et al. A Comprehensive league table of cost-utility ratios and a sub-table of "panel-worthy" studies. Med Decis Making 2000;20:45167.

34. Ko DT, Hebert PR, Coffey CS, et al. Beta-blocker therapy and symptoms of depression, fatigue, and sexual dysfunction. JAMA 2002;288:351-7.

35. Sonnenberg A, Inadomi JM, Bauerfeind P. Reliability block diagrams to model disease management. Med Decis Making 1999;19:180-5.

36. Sonnenberg A, Inadomi JM. Reliability block diagrams to model the management of colorectal cancer. Dig Dis Sci 1999;44:314-21.

37. Poynard T, Lebrec D, Hillon P, et al. Propranolol for prevention of recurrent gastrointestinal bleeding in patients with cirrhosis: A prospective study of factors associated with rebleeding. Hepatology 1987;7:447-51. 
38. Luca A, D'Amico G, La Galla R, et al. TIPS for prevention of recurrent bleeding in patients with cirrhosis: Meta-analysis of randomized clinical trials. Radiology 1999;212:41121.

39. Burroughs AK, Vangeli M. Transjugular intrahepatic portosystemic shunt versus endoscopic therapy: Randomized trials for secondary prophylaxis of variceal bleeding: An updated meta-analysis. Scand J Gastroenterol 2002;37:249 52.

40. Andersen PK, Esbjerg S, Sorensen TI. Multi-state models for bleeding episodes and mortality in liver cirrhosis. Stat Med 2000;19:587-99.

41. D'Amico G, Pagliaro L, Bosch J. The treatment of portal hypertension: A meta-analytic review. Hepatology 1995;22:332-54.

42. Rosellini SR, Miglio F. Beta-blockers for the prevention of variceal haemorrhage in patients with cirrhosis: An updated meta-analysis of randomized controlled trials. Ital J Gastroenterol 1991;23:408-15.

43. Thomsen BL, Sorensen TIA. Project CEVS: Analysis of the treatment effect on recurrent bleeding and death in patients with cirrhosis and esophageal varices. J Hepatol 1998;28:107-14.

44. Escorsell A, Banares R, Garcia-Pagan JC, et al. TIPS versus drug therapy in preventing variceal rebleeding in advanced cirrhosis: A randomized controlled trial. Hepatology 2002;35:385-92.

45. Hoyert DL, Arias E, Smith BL, et al. Deaths: Final data for 1999. Natl Vital Stat Rep 2001;49:1-114.

46. Wiesner R, Edwards E, Freeman R, et al. Model for endstage liver disease (MELD) and allocation of donor livers. Gastroenterology 2003;124:91-6.

47. Laine L, El-Newihi HM, Migikovsky B, et al. Endoscopic ligation compared with sclerotherapy for the treatment of bleeding esophageal varices. Ann Intern Med 1993;119:17.

48. Silverstein FE, Gilbert DA, Tedesco FJ, et al. The national ASGE survey on upper gastrointestinal bleeding. Gastroint Endos 1981;27:73-102.

49. Rossle M, Siegerstetter V, Huber M, et al. The first decade of the transjugular intrahepatic portosystemic shunt (TIPS): State of the art. Liver 1998;18:73-89.

50. Pagliaro L, Burroughs AK, Sorensen TIA, et al. Therapeutic controversies and randomised controlled trials (RCTs): Prevention of bleeding and rebleeding in cirrhosis. Gastroenterol Int 1989;2:71-84.

51. Del Olmo JA, Pena A, Serra MA, et al. Predictors of morbidity and mortality after the first episode of upper gastrointestinal bleeding in liver cirrhosis. J Hepatol 2000;32:1924.

52. Pagliaro L, D’Amico G, Pasta L, et al. Efficacy and efficiency of therapy in portal hypertension. In: Baveno International Consensus Workshop on Definitions M, and Therapeutic Strategies, Portal hypertension II: Proceedings of the Second Baveno International Consensus Workshop. Cambridge, MA: Blackwell Science, 1996:159-79.

53. Morgan AG, Clamp SE. OMGE international upper gastrointestinal bleeding survey, 1978-1986. Scand J Gastroenterol 1988;23:51-8.

54. Sanyal AJ, Freedman AM, Luketic VA, et al. Transjugular intrahepatic portosystemic shunts compared with endoscopic sclerotherapy for the prevention of recurrent variceal hemorrhage. Ann Intern Med 1997;126:849-57.

55. Cabrera J, Maynar M, Granados R, et al. Transjugular intrahepatic portosystemic shunt versus sclerotherapy in the elective treatment of variceal hemorrhage. Gastroenterology 1996;110:832-9.
56. Rossle M, Deibert P, Haag K, et al. Randomised trial of transjugular-intrahepatic-portosystemic shunt versus endoscopy plus propranolol for prevention of variceal rebleeding. Lancet 1997;349:1043-9.

57. Garcia-Villarreal L, Martinez-Lagares F, Sierra A, et al. Transjugular intrahepatic portosystemic shunt versus endoscopic sclerotherapy for the prevention of variceal rebleeding after recent variceal hemorrhage. Hepatology 1999;29:27-32.

58. Merli M, Salerno F, Riggio O, et al. Transjugular intrahepatic portosystemic shunt versus endoscopic sclerotherapy for the prevention of variceal bleeding in cirrhosis: A randomized multicenter trial. Gruppo Italiano Studio TIPS (G.I.S.T.). Hepatology 1998;27:48-53.

59. Sauer P, Benz C, Theilman L, et al. Transjugular intrahepatic portosystemic stent shunt (TIPS) vs. endoscopic banding in the prevention of variceal rebleeding: Final results of a randomized study. Gastroenterology 1998;114:A604

60. Cello JP, Ring EJ, Olcott EW, et al. Endoscopic sclerotherapy compared with percutaneous transjugular intrahepatic portosystemic shunt after initial sclerotherapy in patients with acute variceal hemorrhage. Ann Intern Med 1997;126:858-65.

61. Pagliaro L, D’Amico G, Pasta L, et al. Portal hypertension in cirrhosis: Natural history. In: Groszmann RJ, ed. Portal hypertension: Pathophysiology and treatment. Boston: Blackwell Scientific, 1994:77-92.

62. Cortez-Pinto H, Abrantes A, Esteves AV, et al. Longterm prognosis of patients with cirrhosis of the liver and upper gastrointestinal bleeding. Am J Gastroenterol 1989;84:1239-43.

63. Cooper GS, Bellamy P, Dawson NV, et al. A prognostic model for patients with end-stage liver disease. Gastroenterology 1997;113:1278-88.

64. Schlichting P, Christensen E, Fauerholdt L, et al. Main causes of death in cirrhosis. Scand J Gastroenterol 1983; 18:881-8.

65. D'Amico G, Morabito A, Pagliaro L, et al. Survival and prognostic indicators in compensated and decompensated cirrhosis. Dig Dis Sci 1986;31:468-75.

66. Tait IS, Krige JEJ, Terblanche J. Endoscopic band ligation of oesophageal varices. Br J Surg 1999;86:437-46.

67. Young MF, Sanowski RA, Rasche R. Comparison and characterization of ulcerations induced by endoscopic ligation of esophageal varices versus endoscopic sclerotherapy. Gastrointest Endosc 1993;39:119-22.

68. Cipolletta L, Bianco MA, Rotondano G, et al. Argon plasma coagulation prevents variceal recurrence after band ligation of esophageal varices: Preliminary results of a prospective randomized trial. Gastrointest Endosc 2002;56:467-71.

69. Hou M-C, Lin H-C, Lee F-Y, et al. Recurrence of esophageal varices following endoscopic treatment and its impact on rebleeding: Comparison of sclerotherapy and ligation. J Hepatol 2000;32:202-8.

70. Sarin SK, Govil A, Jain AK, et al. Prospective randomized trial of endoscopic sclerotherapy versus variceal band ligation for esophageal varices: Influence on gastropathy, gastric varices and variceal recurrence. J Hepatol 1997;26:826-32.

71. Goff JS, Reveille RM, Stiegmann GV. Three years experience with endoscopic variceal ligation for treatment of bleeding varices. Endoscopy 1992;24:401-4.

72. Gimson AES, Ramage JK, Panos MZ, et al. Randomised trial of variceal banding ligation versus injection sclerotherapy for bleeding oesophageal varices. Lancet 1993;342:391-4.

73. Stiegmann GV, Goff JS, Michaletz-Onody PA, et al. Endoscopic sclerotherapy as compared with endoscopic 
ligation for bleeding esophageal varices. $\mathrm{N}$ Engl J Med 1992;326:1527-32.

74. Lo G-H, Lai K-H, Cheng J-S, et al. A prospective, randomized trial of sclerotherapy versus ligation in the management of bleeding esophageal varices. Hepatology 1995;22:46671.

75. Quine MA. Prospective audit of upper gastrointestinal endoscopy in two regions of England: Safety, staffing, and sedation methods. Gut 1995;36:462-7.

76. Silvis SE, Nebel O, Rogers G, et al. Endoscopic complications: Results of the 1974 American Society for Gastrointestinal Endoscopy survey. JAMA 1976;235:92830 .

77. Arrowsmith JB, Gerstman BB, Fleischer DE, et al. Results from the American Society for Gastrointestinal Endoscopy/U.S. Food and Drug Administration collaborative study on complication rates and drug use during gastrointestinal endoscopy. Gastrointest Endosc 1991;37:421-7.

78. Freedman AM, Sanyal AJ, Tisnado J, et al. Complications of transjugular intrahepatic portosystemic shunt: A comprehensive review. Radiographics 1993;13:1185-210.

79. Stanley AJ, Jalan R, Forrest EH, et al. Longterm follow up of transjugular intrahepatic portosystemic stent shunt (TIPSS) for the treatment of portal hypertension: Results in 130 patients. Gut 1996;39:479-85.

80. Nazarian GK, Ferral H, Bjarnason H, et al. Effect of transjugular intrahepatic portosystemic shunt on quality of life. Am J Roentgenol 1996;167:963-9.

81. Sahagun G, Benner KG, Saxon R, et al. Outcome of 100 patients after transjugular intrahepatic portosystemic shunt for variceal hemorrhage. Am J Gastroenterol 1997;92:144452.

82. Sanyal AJ, Freedman AM, Luketic VA, et al. The natural history of portal hypertension after transjugular intrahep- atic portosystemic shunts. Gastroenterology 1997;112:88998.

83. LaBerge JM, Somberg KA, Lake JR, et al. Two-year outcome following transjugular intrahepatic portosystemic shunt for variceal bleeding: Results in 90 patients. Gastroenterology 1995;108:1143-51.

84. Canizares RB, Rodriguez-Laiz JM, Martin MC, et al. Transjugular intrahepatic portosystemic shunt with the Strecker stent for control of refractory acute and chronic variceal bleeding: Results in 50 patients. Scand J Gastroenterol 1996;31:285-93.

85. Lind CD, Malisch TW, Chong WK, et al. Incidence of shunt occlusion or stenosis following transjugular intrahepatic portosystemic shunt placement. Gastroenterology 1994; 106:1277-83.

86. Rossle M, Siegerstetter V, Olschewski M, et al. How much reduction in portal pressure is necessary to prevent variceal rebleeding? A longitudinal study in 225 patients with transjugular intrahepatic portosystemic shunts. Am J Gastroenterol 2001;96:3379-83.

87. Kanterman RY, Darcy MD, Middleton WD, et al. Doppler sonography findings associated with transjugular intrahepatic portosystemic shunt malfunction. Am J Roentgenol 1997; 168:467-72.

88. Dodd GD III, Zajko AB, Orons PD, et al. Detection of transjugular intrahepatic portosystemic shunt dysfunction: Value of duplex Doppler sonography. Am J Roentgenol 1995;164:1119-24.

89. Chong WK, Malisch TA, Mazer MJ, et al. Transjugular intrahepatic portosystemic shunt: US assessment with maximum flow velocity. Radiology 1993;189.

90. Viamonte M Jr, LePage J, Lunderquist A, et al. Selective catheterization of the portal vein and its tributaries. Preliminary report. Radiology 1975;114:457-60. 